\title{
Health-promoting properties of bioactive peptides derived from milk proteins in infant food: a review
}

\author{
Vassilios Raikos • Theodore Dassios
}

Received: 10 June 2013 /Revised: 9 September 2013 / Accepted: 19 September 2013 / Published online: 16 October 2013

(C) The Author(s) 2013. This article is published with open access at Springerlink.com

\begin{abstract}
Milk proteins have attracted extensive interest in terms of their bioavailability following ingestion. Enzymatic digestion of dairy products generates numerous peptides with various biological activities. Both human milk and infant formulas based on cow's milk are potential sources of bioactive peptides. This review aims to present current knowledge on the formation and fate of bioactive peptides from milk feeds intended for infants. Emphasis is placed on the source of the bioactive peptides with the nutritional impact of human milk and cow milk-based formulas on infant health being critically discussed from that perspective. Furthermore, the effect of processing and in vitro or in vivo digestion on the release and availability of peptides with bioactive sequences is evaluated. Considerable differences with respect to bioavailability and metabolic effects between the biologically active fragments generated following ingestion of human milk and infant formulas are documented. Peptides from milk protein of bovine origin could be a valuable supplement to human milk as multiple health-promoting properties are attributed to peptide fractions identified in standard cow milk-based infant formulas.
\end{abstract}

Keywords Bioactive $\cdot$ Infant formula $\cdot$ Human milk $\cdot$ Peptide

\section{Introduction}

Milk is very often described as the "ultimate" food which fulfills the nutritional needs of the mammal newborn and ensures safe development and growth during the first stages of its life (Mills et al. 2011). Individual milk components contribute to the high biological and nourishing value of this food. Milk proteins, for instance, are known to exert various actions that promote human health. These actions include stimulation of

\footnotetext{
V. Raikos $(\bowtie)$

Rowett Institute of Nutrition \& Health, University of Aberdeen, Greenburn Road, Bucksburn, Aberdeen AB21 9SB, UK

e-mail: v.raikos@abdn.ac.uk

T. Dassios

Addenbrooke's Hospital, Cambridge University Hospitals NHS Foundation Trust, Hills Road, Cambridge CB2 0SW, UK
} 
the immune system, digestion and absorption of nutritional elements, development of endogenous defense mechanisms against bacteria, fungi and viruses, prebiotic effects, and others (Lönnerdal 2003).

Recently, milk proteins have attracted extensive interest in terms of their bioavailability following ingestion. In vivo digestion of milk proteins within the gastrointestinal tract results in the release of peptides with new biological properties compared to the ones exhibited by the intact, precursor molecule (Chatterton et al. 2004). Many of these protein fragments, also known as bioactive peptides, consist of approximately 3-20 amino acids, which are encrypted within the parental protein and become activated following their release, induced by the action of gastric and pancreatic enzymes (Kekkonen 2009; Korhonen 2009). In addition, biologically active peptides may be formed during food processing. In vitro hydrolysis of milk proteins is a common method for producing hydrolyzed peptide fragments used for hypoallergenic infant formulas (Korhonen et al. 1998). The peptides generated either in vitro or in vivo differ markedly with respect to their biological activities depending on the digestion process and/or the parental protein from which they are released.

The identification of bioactive milk peptides was first reported in 1950 (Mellander 1950). Since then, numerous reports document the presence of peptides which exert some physiological effect on the human body in milk or milk-based products (Beaulieu et al. 2007; Foltz et al. 2007; Haque et al. 2009; Hayes et al. 2006; Kamau et al. 2010; LeBlanc et al. 2002; Meisel and Fitzgerald 2000; Nagpal et al. 2011). However, to the best of our knowledge, limited studies exist which focus on the health-promoting properties of milk peptides detected in infant feeding regimens. This paper reviews recent research on the formation and fate of bioactive peptides from milk feeds intended for infants. Furthermore, suggestions based on recently published research for improvement of the nutritional value of infant formulas through the inclusion of milk-derived peptides serving as functional ingredients are provided.

\section{Human milk versus infant formula as a potential source of bioactive peptides}

Human milk is considered the reference standard for the manufacture of infant formulas. Thus, the latter are designed to simulate the content and the performance of the former in an attempt to mimic the effect of breast milk on metabolic and other physiologic functions. In addition to standard formulas, hydrolysates of cows' milk are also available for infant nutrition usually supplied as a hypoallergenic therapeutic or preventive formulation for allergenized or sensitized newborns (Caffarelli et al. 2002).

Qualitative and quantitative differences exist between human milk and infant formulas, and these include protein compositional dissimilarities. For instance, cows' milk-based infant formulas contain three to four times higher protein content compared to human milk (Rudloff and Kunz 1997). Furthermore, caseins dominate the protein fraction in bovine milk $(\sim 80 \%)$, whereas the principal class of protein in human milk is whey, particularly during the first days of lactation (Kunz and Lönnerdal 1989; Kunz and Lönnerdal 1990). Proteomic analysis indicates that human milk does not contain $\beta$ lactoglobulin and $\alpha_{\mathrm{s} 2}$-casein, whereas lactoferrin and $\alpha$-lactalbumin are the main protein components (Armaforte et al. 2010). The same study provides further evidence on qualitative similarities in terms of the protein profile of infant formula and bovine milk 
with $\alpha_{\mathrm{s} 1}$-casein, $\alpha_{\mathrm{s} 2}$-casein, $\beta$-casein, and $\beta$-lactoglobulin being the most abundant proteins. Other major differences between human and bovine milk proteins such as the different glycosylation degree of immunoglobulins, lactoferrin, and casein have been documented (Nwosu et al. 2012).

Considering human milk as the gold standard, several attempts have been made to "humanize" infant formulas. Commercially available products include whey-enriched infants formulas based on cow's milk. In this case, formulations include a casein-to-whey protein ratio of approximately 40:60, which is somewhat closer to the one encountered in human milk. Whey-dominant formulas which resemble the human milk compositional standard seem to a have the same impact on growth of premature infants as compared to casein-dominant formulations (Bernbaum et al. 1989). However, other advantages particularly for low-birth weight and preterm infants may be related to whey-dominant formulas, which is an expected finding as milk is a biological fluid that has evolved to meet the nutritional demands of the human species (Rudloff and Kunz 1997). Other attempts to narrow the gap between the protein content of human milk and infant formulas involve the fortification of infant formulas with purified proteins of bovine origin, which are abundant in human milk such as $\alpha$-lactalbumin, lactoferrin, and others (Chatterton et al. 2004).

Despite the efforts to replicate the protein compositional recipe of human milk, infant formulas and protein hydrolysate products display qualitative and quantitative differences in terms of protein content that may affect physiological process in the newborn. In general, formulas provide a different profile of amino acids in addition to more protein content. Differences in the parental (intact) proteins result most likely in the generation of peptides with different biological activities following the process of digestion. It has been documented that hydrolysis products of the native human $\alpha$-caseins generated by the proteolytic activity of plasmin cannot be detected in commercial formulations intended for infants (Armaforte et al. 2010). This is because bovine plasmin preferentially acts upon $\beta$-casein (Fox and Kelly 2005). As a result, considerable differences are expected in terms of bioavailability and metabolic effects between the biologically active fragments generated following ingestion of human milk, infant formulas, and hydrolyzed products, which may affect infant growth.

\section{Aspects of in vivo and in vitro generation of bioactive peptides}

There are various ways for releasing bioactive peptides. First, milk proteins may be digested in vitro during food processing by maturation with selected enzymes. In this case, where milk is fermented with a proteolytic culture, the process is carefully controlled (enzyme specificity, temperature, incubation time, etc.), and thus the release of bioactive peptides may be predicted (Exl 2001). Common enzymes in the commercial production of bioactive peptides via in vitro digestion include pepsin, trypsin, and chymotrypsin (Korhonen et al. 1998). Bioactive peptides may also be generated following ingestion in vivo by either digestive enzymes or by microbial enzymes (Kekkonen 2009). Thus milk proteins during their passage through the digestive system may be the target of enzymes produced either by the human body or by microorganisms which normally inhabit the gastrointestinal tract. A wide range of enzymes with different cleavage sites may act throughout the whole gastrointestinal tract and under conditions 
which may differ depending on various physiological factors (Antalis et al. 2007). In this case, the process is far less easy to control and to monitor. This is the reason why in vitro digestion, also known as simulated gastrointestinal digestion (SGID), is often employed to investigate the stability of milk proteins and the fate of bioactive peptides. SGID takes into account key factors affecting the digestion process such as the rates of gastric emptying, which are used to determine the period of incubation with gastric proteases, and changes in gastric $\mathrm{pH}$ value which determine to a large extent the enzyme activity (De Noni 2008).

Nevertheless, SGID may be regarded as an oversimplified method to determine the fate of precursor milk proteins. In reality, things are more complicated as physiological processes in vivo are not static, and the environment within the gastrointestinal tract of an infant is subject to changes with time or cause. Gastric $\mathrm{pH}$, for instance, is known to be high in early neonatal life and has been determined to be 6.0 in term newborn infants with the tendency to decrease sharply during the first $24 \mathrm{~h}$ of life (Widstrom et al. 1988). According to Chatterton et al. (2004), proteins in human milk and infant formula showed a $\mathrm{pH}$-dependent extent of hydrolysis when incubated with gastric juice in a $\mathrm{pH}$ range between 6.5 and 2.0. This is somewhat expected as gastric enzymes show optimum activity at specific $\mathrm{pH}$ values. Furthermore, the concentration of milk proteases (e.g., plasmin) present in breast milk is increased for premature infants, which results in extensive hydrolysis of milk proteins to facilitate the digestion process (Armaforte et al. 2010). This could in turn affect the biological activity of the digests, as peptides have to be absorbed from the intestine and reach their target cells in adequate concentrations. As a result, one may conclude that the digestion process of milk proteins in vivo is a complex process and depends on various factors which cannot be adequately simulated in vitro. In vivo studies are more reliable in order to draw safe conclusions with respect to the formation of bioactive peptides following the ingestion of human milk and infant formulas. The formation of bioactive peptides in vivo following the digestion of milk proteins has been documented in the past both in human (Boutrou et al. 2013; Foltz et al. 2007) and animal (Bouzerzour et al. 2012) models. According to these studies, although evidence exists to support their presence in the human and piglet gastrointestinal tract, further research is required to investigate the physiologic conditions which would allow the bioactive peptides to exert their bioactivity.

\section{Bioactive peptides in human milk and infant formulas}

Peptides released from in vivo or in vitro digestion of milk proteins are known to affect major systems such as the cardiovascular, nervous, digestive, and immune system. According to Hayes et al. (2007), bioactive peptides from milk having a physiological impact on human body can be categorized as antihypertensive, antithrombotic, opioid, casein phosphopeptides, antimicrobial, cytomodulatory, immunomodulatory, and miscellaneous. Recent findings indicate that milk peptides can have additional physiological effects such as antioxidant activity or may even possess functional significance which is not yet clearly understood. Therefore, the consideration of milk peptides as dietary supplements or food additives could be promising for the food industry in the future. Table 1 summarizes the bioactive peptides identified in both human and bovine milk with potential beneficial effect on human health. 
Table 1 Biofunctional peptides derived from human and bovine milk proteins with effects on human health

\begin{tabular}{|c|c|c|c|c|c|}
\hline Function & $\begin{array}{l}\text { Precursor } \\
\text { protein }\end{array}$ & Fragment & Peptide sequence & Origin & Reference \\
\hline Antihypertensive & $\beta$-lactoglobulin & $\mathrm{f}(40-42)$ & RVY & Bovine & (Hernández-Ledesma et al. 2004) \\
\hline Antihypertensive & $\beta$-lactoglobulin & f 122-124) & LVR & Bovine & (Hernández-Ledesma et al. 2004) \\
\hline Antihypertensive & $\beta$-casein & $f(60-66)$ & YPFPGPI & Bovine & (Hernández-Ledesma et al. 2004 \\
\hline Antihypertensive & $\beta$-casein & $\mathrm{f}(134-138)$ & HLPLP & Bovine & (Hernández-Ledesma et al. 2004) \\
\hline Antihypertensive & $\alpha$-lactalbumin & $f(59-60)$ & IW & Bovine & (Martin et al. 2008) \\
\hline Antihypertensive & $\beta$-lactoglobulin & $\mathrm{f}(46-48)$ & LKP & Bovine & (Català-Clariana et al. 2010) \\
\hline Antihypertensive & $\beta$-lactoglobulin & $\mathrm{f}(142-145)$ & ALPM & Bovine & (Català-Clariana et al. 2010) \\
\hline Antihypertensive & $\beta$-lactoglobulin & $f(15-20)$ & VAGTWY & Bovine & (Català-Clariana et al. 2010) \\
\hline Antihypertensive & $\alpha$ s2-casein & $f(201-203)$ & IPY & Bovine & (Català-Clariana et al. 2010) \\
\hline Antihypertensive & $\beta$-casein & $f(63-68)$ & PGPIHNI & Bovine & (Català-Clariana et al. 2010) \\
\hline Antihypertensive & $\beta$-casein & $\mathrm{f}(125-129)$ & HLPLP & Human & (Hernández-Ledesma et al. 2007) \\
\hline Antihypertensive & $\beta$-casein & $\mathrm{f}(80-90)$ & TPVVVPPFLQP & Human & (Bouzerzour et al. 2012) \\
\hline Antioxidant & Unknown & N/A & YGYTGA & Human & (Tsopmo et al. 2011) \\
\hline Antioxidant & Unknown & $\mathrm{N} / \mathrm{A}$ & ISELGW & Human & (Tsopmo et al. 2011) \\
\hline Antioxidant & $\beta$-casein & $\mathrm{f}(154-160)$ & WSVPQPK & Human & (Hernández-Ledesma et al. 2007) \\
\hline Antithrombotic & $\mathrm{K}$-casein & $\mathrm{f}(114-124)$ & IAIPPKKIQDK & Human & (Chabance et al. 1995) \\
\hline Antithrombotic & $\mathrm{K}$-casein & $\mathrm{f}(106-116)$ & MAIPPKKNQDK & Bovine & (Chabance et al. 1995) \\
\hline Opioid & $\beta$-casein & $\mathrm{f}(60-66)$ & YPFPGPI & Bovine & $\begin{array}{l}\text { (De Noni, 2008; De Noni } \\
\text { and Cattaneo, 2010) }\end{array}$ \\
\hline Opioid & $\beta$-casein & $\mathrm{f}(60-64)$ & YPFPG & Bovine & (Jarmolowska et al. 2007a) \\
\hline Opioid & $\mathrm{K}$-casein & $\mathrm{f}(25-34)$ & YIPIQYVLSR & Bovine & (Jarmolowska et al. 2007a) \\
\hline Opioid & $\beta$-casein & $\mathrm{f}(51-55)$ & YPFVE & Human & (Jarmolowska et al. 2007b) \\
\hline Opioid & $\beta$-casein & $\mathrm{f}(51-57)$ & YPFVEPI & Human & (Jarmolowska et al. 2007b) \\
\hline Immunomodulatory & $\beta$-casein & $f(60-66)$ & YPFPGPI & Bovine & (Bouzerzour et al. 2012) \\
\hline Mineral binding & $\alpha$ s1-casein & - & $\begin{array}{l}\text { SpSpSpEE } \\
\quad \text { (cluster sequence) }\end{array}$ & Bovine & $\begin{array}{l}\text { (Miquel et al. 2006; Miquel et al. } \\
\text { 2005) }\end{array}$ \\
\hline Mineral binding & $\alpha$ s2-casein & - & $\begin{array}{l}\text { SpSpSpEE } \\
\quad \text { (cluster sequence) }\end{array}$ & Bovine & $\begin{array}{l}\text { (Miquel et al. 2006; Miquel et al. } \\
\text { 2005) }\end{array}$ \\
\hline Mineral binding & $\beta$-casein & - & $\begin{array}{l}\text { SpSpSpEE } \\
\quad \text { (cluster sequence) }\end{array}$ & Bovine & (Miquel et al. 2005) \\
\hline Antimicrobial & $\mathrm{K}$-casein & $\mathrm{f}(106-169)$ & - & Bovine & (Brück et al. 2003) \\
\hline
\end{tabular}

\subsection{Effects on the cardiovascular system}

The release of angiotensin converting enzymes (ACE)-inhibitory peptides by SGID of infant formulas has been documented by Hernández-Ledesma et al. (2004). According to this study, enzymatically hydrolyzed casein and whey formulas exhibited higher ACEinhibitory activities than non-hydrolyzed milk protein formulations. It was hypothesized that low molecular weight peptides $(<3,000 \mathrm{Da})$ were mainly responsible for this activity with several potent peptides being identified ( $\beta$-Lg: RVY and LVR; $\beta$-casein: YPFPGPI and HLPLP). The size of the hydrolyzed fragments could be critical in terms of the antihypertensive activity as di- and tripeptides are easily absorbed in the intestine and may reach the blood and other target sites (Hara et al. 1984). Furthermore, SGID had a

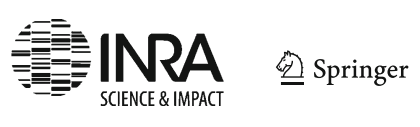


positive impact on the unhydrolyzed samples and did not affect the hydrolyzed wheybased formulas with respect to ACE inhibition. This suggests that whey hydrolysates survive physiological digestion. Similar findings were reported by other researchers (Martin et al. 2008) who compared the ACE-inhibitory activity of hypoallergenic formulas and breast milk. The dipeptide Ile-Trp (IW), present at positions 59-60 in bovine $\alpha$-lactalbumin from hypoallergenic formulas, was identified as the most potent ACE inhibitor in this study. According to the authors, conventional milk-based formulas and breast milk samples did not exhibit ACE inhibition. In agreement with the previous studies, SGID did not affect the overall inhibitory effect of the hydrolysate formula, indicating that the peptides survive gastrointestinal hydrolysis. The presence of peptides with potent ACE-inhibitory activity was also confirmed in more recent studies with hypoallergenic formulas containing partially hydrolyzed whey, highly hydrolyzed whey and casein, and highly hydrolyzed casein bovine proteins (Català-Clariana et al. 2010). In this case, five bioactive peptides namely LKP, IPY, ALPM, PGPIHN, and VAGTWY were detected by means of capillary electrophoresis time-of-flight mass spectrometry.

In other studies, breast milk and bovine milk protein-based infant formulas were digested with pepsin and pancreatin and the contribution of the fragments generated to ACE-inhibitory activity was determined (Hernández-Ledesma et al. 2007). This study revealed that the peptide fraction obtained from human breast milk showed limited ACE-inhibition compared with the one exhibited by the corresponding fraction obtained from infant formulas. According to the authors, this is due to the different peptide fragments obtained from human milk samples and infant formulas following hydrolysis with the specific enzymes. Interestingly, only one peptide (HLPLPL) was common between the digests of human and bovine origin. Nevertheless, a potent ACE inhibitor was identified in human milk and corresponded to the $\beta$-casein fragment $f(125-129)$ with the sequence HLPLP. In this case, it was hypothesized that the presence of the amino acid proline at the C-terminal end could be crucial in terms of the activity observed (Cheung et al. 1980). Finally, the peptide f 80-90 (TPVVVPPFLQP) from $\beta$-casein which is known to possess antihypertensive activities was detected in animal models fed with infant formulas (Bouzerzour et al. 2012). In this study, piglets were used as a model to study aspects of protein digestion and absorption in human infants.

The production of reactive oxygen species (ROS) is part of normal cell metabolism. In some cases, such as in preterm infants, high levels of ROS are produced that disturb the redox balance and result in a state formerly known as oxidative stress (Buonocore et al. 2002). Oxidative stress induced by free radicals is linked to the pathogenesis of various diseases including heart disease (Aruoma 1998). The antioxidant potential of human milk has been documented in the past (Friel et al. 2002). According to Samaranayaka and Li-Chan (2011), peptides and proteins are implicated in the overall antioxidative status of cells and contribute towards maintaining the health of biological tissue. Recent findings indicate that peptides released from human milk after digestion with pepsin and pancreatin could be beneficial with respect to antioxidant activity (Tsopmo et al. 2011). In this study, the peptides YGYTGA and ISELGW showed high radical scavenging activity, and this property was attributed to the presence of the amino acid tryptophan which can break radical chain reactions thanks to the donation of the hydrogen attached to the nitrogen of its indole ring. The same hypothesis was made by other researchers who reported moderate antioxidant activity by peptides 
derived from digested human samples with pepsin and pancreatin (Hernández-Ledesma et al. 2007). In this case, the peptide with the highest antioxidant activity was WSVPQPK, which also contains tryptophan and, thus, may serve as hydrogen donor and/or free radical scavenger.

Peptides of human (IAIPPKKIQDK) and bovine (MAIPPKKNQDK) origin with antithrombotic effects were detected at physiologically active levels in the plasma of newborn infants after breastfeeding or ingestion of cow milk-based formula (Chabance et al. 1995). These peptides, known as K-caseinoglycopeptides, exert their biological function by reducing platelet aggregation and enhancing fibrinolysis, which results in the prevention of thrombosis development.

\subsection{Effects on the nervous system}

Opioid peptides are small molecules which are synthesized in vivo and may function both as hormones and neurotransmitters. These peptides depending on their bioactivity are classified as opioid agonists or antagonists. $\beta$-casomorphins derived from $\beta$-casein, and particularly $\beta$-casomorphin-5 (BCM5) and $\beta$-casomorphin-7 (BCM7), are the best-known opioid peptides (Schlimme et al. 1989). The release of BCM7 from commercial milk-based infant formulas following SGID was confirmed (De Noni 2008). The peptides identified were released from genetic variants A1 and B of $\beta$-casein. According to the European Food Safety Authority, there is no established relationship between the dietary intake of BCM7 and non-communicable diseases (EFSA European Food Safety Authority 2009). Although no safe conclusions can be drawn at the moment regarding the minimum amount of BCM7 capable to elicit pharmacological effects in vivo or ex vivo, further studies confirm its release by the action of gastrointestinal proteases during in vitro digestion in commercial infant formulas at concentrations between 0.04 and $0.21 \mathrm{mg} .1$ (De Noni and Cattaneo 2010). The presence of four opioid peptides in the commercially available Humana formula (Humana $\mathrm{GmbH}$, Germany) for newborns after digestion with pepsin and trypsin has been documented (Jarmolowska et al. 2007a). Both opioid agonists (BCM5) and antagonists (casoxin $\mathrm{C}$, casoxin 6, and lactoferroxin $\mathrm{A}$ ) deriving from $\beta-$, $\mathrm{k}$-casein, and lactoferrin were identified. All four opioid peptides were detected in the formulas prior to enzymatic hydrolysis at concentrations between 0.075 to $0.39 \mu \mathrm{g} . \mathrm{ml}$ with their concentration to rise sharply after enzyme hydrolysis. The presence of BCM5 and BCM7 in human milk has also been confirmed with the content of the opioid peptides being dependent on the lactation stage (Jarmolowska et al. 2007b).

BCM7 and related compounds have been linked in the past with the development of human diseases such as juvenile diabetes, heart disease, autism, and schizophrenia (McLachlan, 2001). Although evidence regarding the abundance of such peptides in infant formulas is inconclusive, the formation of BCMs in infant feeds following SGID has been demonstrated. The in vivo effects of these peptides on the human physiology have not yet been fully described.

\subsection{Other health-promoting effects}

It has been demonstrated that protein peptides exert biological action on the metabolism of minerals. Minerals play a multifunctional role in human health. They participate in 
bone structure and teeth and are involved in several metabolic processes such as energy production, nutrient absorption, protein building, and blood formation (Soetan et al. 2010). Casein phosphopeptides (CPPs) deriving from the digestion of milk proteins may act as mineral carriers and affect their bioavailability in the human body (Meisel and Fitzgerald 2003). Recent studies document the presence of bioactive peptides with mineral carrier properties in infant formulas (Miquel et al. 2006). The peptides originating from $\alpha_{\mathrm{s} 1}$ and $\alpha_{\mathrm{s} 2}$-casein survived SGID with pepsin and pancreatin, and their identified molecular masses were in the range of 1,400 to 9,600 Da, which makes them good candidates for intestinal absorption. According to the authors, calcium could be bound preferentially to CPPs with the cluster sequence SpSpSpEE and iron and zinc to CPPs with the phosphorylated cluster and phosphoserine residues. The release of CPPs with metal-chelating properties following SGID of infant formulas was also reported in previous studies (Miquel et al. 2005). Many of these CPPs were only detected in probiotic formulas indicating that they are formed by the action of bifidobacteria.

Dietary protein is known to play a major role in the human body's defense mechanism against infection by either stimulating the immune system (immunomodulatory) or contributing to the inhibition of microbial growth (antimicrobial). Supplementation of infant formulas with $\alpha$-lactalbumin and glycomacropeptide (GMP), a derivative of $\mathrm{K}$ casein, which were digested with pepsin and pancreatin, resulted in decreased counts of Bacteroides (Brück et al. 2003). This was attributed to the ability of the supplemented formula to mimic the fermentative qualities of breast milk and induce the growth of protective microflora in the gastrointestinal tract. Furthermore, the bacteriostatic and bactericidal effects of $\alpha$-lactalbumin and GMP have been demonstrated when a significant reduction in enteropathogenic bacteria including enteropathogenic Escherichia coli and Salmonella was observed following supplementation of the infant formulas with the specific milk substrates (Brück et al. 2003). The release of bioactive peptides with immunomodulatory activities from infant formulas is also documented by more recent studies. In this case, the peptide f 60-66 (YPFPGPI) from $\beta$-casein was detected following in vivo digestion by piglets which were fed with infant formulas (Bouzerzour et al. 2012). According to the findings of this study, whey proteins were more resistant to enzymatic digestion in the stomach of piglets compared to caseins with the latter being hydrolyzed to a large extent just 30 min after meal ingestion.

\section{Conclusions}

Extensive research has underlined the important contribution of breastfeeding in promoting general health, growth, and development of the human species and the significant reduction in the risk of acute and chronic diseases (Gartner et al. 2005). Proteins contribute to the nutritional value of milk and also have other biological roles as intact molecules, as many of them are resistant to the effects of digestion (Chatterton et al. 2004). On the other hand, digestion of milk proteins in the gastrointestinal tract results in the release of bioactive agents which may affect several physiological processes. Despite the fact that many of these bioactive peptides have been identified as integral parts of milk proteins, their contribution in human nutrition has not been sufficiently described in the literature. Furthermore, limited information is available with respect to their passage through the human, and most importantly the infant's digestive tract. Up-to-date, bioactive peptides 
have been identified in both human milk and cow milk-based infant formulas, which differ in their amino acid profiles and properties. Modern methods of analysis enable fast and reliable separation and identification of bioactive peptides in milk-derived products (Català-Clariana et al. 2013). The peptides identified following SGID have antihypertensive, antioxidant, antithrombotic, opioid, mineral carrier, and immunogenic effects on human physiology. Further research in this field is required to establish the beneficial role of human or bovine milk from that perspective. It seems likely though that peptides from milk protein of bovine origin could be a valuable supplement to human milk. The manufacture of "chimeric" infant formulas with multiple health-promoting effects could be used as a model example in the future for the manufacture of ultimately functional foods.

Open Access This article is distributed under the terms of the Creative Commons Attribution License which permits any use, distribution, and reproduction in any medium, provided the original author(s) and the source are credited.

\section{References}

Antalis TM, Shea-Donohue T, Vogel SN, Sears C, Fasano A (2007) Mechanisms of disease: protease functions in intestinal mucosal pathobiology. Nat Clin Pract Gastroenetrol Heapatol 4:393-402

Armaforte E, Curran E, Huppertz T, Ryan CA, Caboni MF, O’Connor PM, Ross RP, Hirtz C, Sommerer N, Chevalier F, Kelly AL (2010) Proteins and proteolysis in preterm and term human milk and possible implications for infant formulae. Int Dairy J 20:715-723

Aruoma OI (1998) Free radicals, oxidative stress, and antioxidants in health and disease. J Am Oil Chem Soc 75:199-212

Beaulieu J, Dubuc R, Beaudet N, Dupont C, Lemieux P (2007) Immunomodulation by a malleable matrix composed of fermented whey proteins and lactic acid bacteria. J Med Food 10:67-72

Bernbaum JC, Sasanow SR, Churella HR, Daft A (1989) Growth and metabolic response of premature infants fed whey- or casein-dominant formulas after hospital discharge. J Pediatr 115:652-656

Boutrou R, Gaudichon C, Dupont D, Jardin J, Airinei G, Marsset-Baglieri M, Benamouzig R, Tomé D, Leonil J (2013) Sequential release of milk protein-derived bioactive peptides in the jejunum in healthy humans. Am J Clin Nutr 97:1314-1323

Bouzerzour K, Morgan F, Cuinet I, Bonhomme C, Jardin J, Le Huëou-Luron I, Dupont D (2012) In vivo digestion of infant formula in piglets: protein digestion kinetics and release of bioactive peptides. Brit $\mathrm{J}$ Nutr 108:2105-2114

Brück WM, Graverholt G, Gibson GR (2003) A two-stage continuous culture system to study the effect of supplemental $\alpha$-lactalbumin and glycomacropeptide on mixed cultures of human gut bacteria challenged with enteropathogenic Escherichia coli and Salmonella serotype Typhimurium. J Appl Microbiol 95:44-53

Buonocore G, Perrone S, Longini M, Vezzosi P, Marzocchi B, Paffetti P, Bracci R (2002) Oxidative stress in preterm neonates at birth and on the seventh day of life. Pediatr Res 52:46-49

Caffarelli C, Plebani A, Poiesi C, Petroccione T, Spattini A, Cavagni G (2002) Determination of allergenicity to three cow's milk hydrolysates and an amino acid-derived formula in children with cow's milk allergy. Clin Exp Allergy 32:74-79

Català-Clariana S, Benavente F, Giménez E, Barbosa J, Sanz-Nebot V (2010) Identification of bioactive peptides in hypoallergenic infant milk formulas by capillary electrophoresis-mass spectrometry. Anal Chim Acta 683:119-125

Català-Clariana S, Benavente F, Giménez E, Barbosa J, Sanz-Nebot V (2013) Identification of bioactive peptides in hypoallergenic infant milk formulas by CE-TOF-MS assisted by semiempirical model of electromigration behavior. Electrophoresis 34:1886-1894

Chabance B, Jollès P, Izquierdo C, Mazoyer E, Francoual C, Drouet L, Fiat A-M (1995) Characterization of an antithrombotic peptide from K-casein in newborn plasma after milk ingestion. Brit J Nutr 73:583-590

Chatterton DEW, Rasmussen JT, Heegaard CW, Sørensen ES, Petersen TE (2004) In vitro digestion of novel milk protein ingredients for use in infant formulas: Research on biological functions. Trends Food Sci Technol 15:373-383

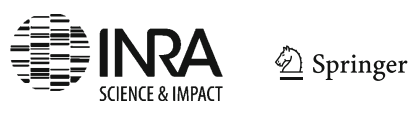


Cheung H-S, Wang F-L, Ondetti MA, Sabo EF, Cushman DW (1980) Binding of peptide substrates and inhibitors of angiotensin-converting enzyme. Importance of the $\mathrm{COOH}$-terminal dipeptide sequence. $\mathrm{J}$ Biol Chem 255:401-407

De Noni I (2008) Release of $\beta$-casomorphins 5 and 7 during simulated gastrointestinal digestion of bovine $\beta$-casein variants and milk-based infant formulas. Food Chem 110:897-903

De Noni I, Cattaneo S (2010) Occurrence of $\beta$-casomorphins 5 and 7 in commercial dairy products and in their digests following in vitro-simulated gastrointestinal digestion. Food Chem 119:560-566

EFSA European Food Safety Authority (2009) Review of the potential health impact of $\beta$-casomorphins and related peptides. Sci Rep 231:1-107

Exl BM (2001) A review of recent developments in the use of moderately hydrolyzed whey formulae in infant nutrition. Nutr Res 21:355-379

Foltz M, Meynen EE, Bianco V, van Platerink C, Koning TM, Kloek J (2007) Angiotensin converting enzyme inhibitory peptides from a lactotripeptide-enriched milk beverage are absorbed intact into the circulation. J Nutr 137:953-958

Fox PF, Kelly AL (2005) Indigenous enzymes in milk: overview and historical aspects - part 1. Int Dairy J 16:500-516

Friel JK, Martin SM, Langdon M, Herzberg GR, Buettner GR (2002) Milk from mothers of both premature and full-term infants provides better antioxidant protection than does infant formula. Pediatr Res 51:612-618

Gartner LM, Morton J, Lawrence RA, Naylor AJ, O'Hare D, Schanler RJ, Eidelman AI (2005) Breastfeeding and the use of human milk. Pediatrics 115:496-506

Haque E, Chand R, Kapila S (2009) Biofunctional properties of bioactive peptides of milk origin. Food Rev Int 25:28-43

Hara H, Funabiki R, Iwata M, Yamazaki K (1984) Portal absorption of small peptides in rats under unrestrained conditions. J Nutr 114:1122-1129

Hayes M, Ross RP, Fitzgerald GF, Hill C, Stanton C (2006) Casein-derived antimicrobial peptides generated by Lactobacillus acidophilus DPC6026. Appl Environ Microbiol 72:2260-2264

Hayes M, Stanton C, Fitzgerald GF, Ross RP (2007) Putting microbes to work: dairy fermentation, cell factories, and bioactive peptides. Part II: bioactive peptide functions. Biotech J 2:435-449

Hernández-Ledesma B, Amigo L, Ramos M, Recio I (2004) Release of angiotensin converting enzymeinhibitory peptides by simulated gastrointestinal digestion of infant formulas. Int Dairy J 14:889-898

Hernández-Ledesma B, Quirós A, Amigo L, Recio I (2007) Identification of bioactive peptides after digestion of human milk and infant formula with pepsin and pancreatin. Int Dairy J 17:42-49

Jarmolowska B, Sidor K, Iwan M, Bielikowicz K, Kaczmarski M, Kostyra E, Kostyra H (2007a) Changes of ß-casomorphin content in human milk during lactation. Peptides 28:1982-1986

Jarmolowska B, Szlapka-Sienkiewicz E, Kostyra E, Kostyra H, Mierzejewska D, DarmochwalMarcinkiewicz K (2007b) Opioid activity of Humana formula for newborns. J Sci Food Agric $87: 2247-2250$

Kamau SM, Lu RR, Chen W, Liu XM, Tian FW, Shen Y, Gao T (2010) Functional significance of bioactive peptides derived from milk proteins. Food Rev Int 26:386-401

Kekkonen R (2009) Bioactive milk protein and peptide functionality. In: Corredig M (ed) Dairy Derived Ingredients. Woodhead Publishing Limited and CRC Press LLC

Korhonen H (2009) Milk-derived bioactive peptides: from science to applications. J Funct Foods 1(2):177187

Korhonen H, Pihlanto-Leppälä A, Rantamäki P, Tupasela T (1998) Impact of processing on bioactive proteins and peptides. Trends Food Sci Technol 9(8):307-319

Kunz C, Lönnerdal B (1989) Human milk protein: separation of whey proteins and their analysis by polyacrylamide gradient gel electrophoresis, fast protein liquid chromatography (FPLC), gel filtration, and anion-exchange chromatography. Am J Clin Nutr 49:464-470

Kunz C, Lönnerdal B (1990) Human-milk proteins: analysis of casein and casein subunits by anion-exchange chromatography, gel electrophoresis, and specific staining methods. Am J Clin Nutr 51:37-46

LeBlanc JG, Matar C, Valdez JC, LeBlanc J, Perdigon G (2002) Immunomodulating effects of peptidic fractions issued from milk fermented with Lactobacillus helveticus. J Dairy Sci 85:2733-2742

Lönnerdal B (2003) Nutritional and physiologic significance of human milk proteins. Am J Clin Nutr $77: 1537 \mathrm{~S}-1543 \mathrm{~S}$

Martin M, Wellner A, Ossowski I, Henle T (2008) Identification and quantification of inhibitors for angiotensin-converting enzyme in hypoallergenic infant milk formulas. J Agric Food Chem $56: 6333-6338$ 
McLachlan CNS (2001) ß-casein A1, ischaemic heart disease mortality, and other illnesses. Med Hypotheses 56:262-272

Meisel H, Fitzgerald RJ (2000) Opioid peptides encrypted in intact milk protein sequences. Brit J Nutr 84:S27-S31

Meisel H, Fitzgerald RJ (2003) Biofunctional peptides from milk proteins: mineral binding and cytomodulatory effects. Curr Pharm Des 9:1289-1295

Mellander O (1950) The physiological importance of the casein phosphopeptide calcium salts. II. Peroral calcium dosage of infants. Acta Soc Med Ups 55:247-255

Mills S, Ross RP, Hill C, Fitzgerald GF, Stanton C (2011) Milk intelligence: mining milk for bioactive substances associated with human health. Int Dairy J 21:377-401

Miquel E, Alegría A, Barberá R, Farré R (2006) Casein phosphopeptides released by simulated gastrointestinal digestion of infant formulas and their potential role in mineral binding. Int Dairy J 16:992-1000

Miquel E, Gómez JA, Alegría A, Barberá R, Farré R, Recio I (2005) Identification of casein phosphopeptides released after simulated digestion of milk-based infant formulas. J Agric Food Chem 53:3426-3433

Nagpal R, Behare P, Rana R, Kumar A, Kumar M, Arora S, Morotta F, Jain S, Yadav H (2011) Bioactive peptides derived from milk proteins and their health beneficial potentials: an update. Food Funct 2:18-27

Nwosu CC, Aldredge DL, Lee H, Lerno LA, Zivkovir AM, German JB, Lebrilla CB (2012) Comparison of the human and bovine milk N-Glycome via high-performance microfluidic chip liquid chromatography and tandem mass spectrometry. J Prot Res 11:2912-2924

Rudloff S, Kunz C (1997) Protein and nonprotein nitrogen components in human milk, bovine milk, and infant formula: quantitative and qualitative aspects in infant nutrition. J Pediatr Gastroenterol Nutr 24:328-344

Samaranayaka AGP, Li-Chan ECY (2011) Food-derived peptidic antioxidants: a review of their production, assessment, and potential applications. J Funct Foods 3(4):229-254

Schlimme E, Meisel H, Frister H (1989) Bioactive sequences in milk proteins. In Barth C, Schlimme E. (eds.) Milk proteins: Nutritional, clinical, functional and technological aspects. Steinkoppf, Darmsdadt, Springer

Soetan KO, Olaiya CO, Oyewole OE (2010) The importance of mineral elements for humans, domestic animals, and plants - a review. Afr J Food Sci 4:200-222

Tsopmo A, Romanowski A, Banda L, Lavoie JD, Jenssen H, Friel JK (2011) Novel antioxidative peptides from enzymatic digestion of human milk. Food Chem 126:1138-1143

Widstrom AM, Christensson K, Ransjo-Arvidson AB, Mathiesen AS, Winberg J, Uvnas-Moberg K (1988) Gastric aspirates of newborn infants: $\mathrm{pH}$, volume, and levels of gastrin- and somatostatin-like immunoreactivity. Acta Pediatr Scand 77:502-508 